\title{
ASSESSING OF MALNUTRITION IN PATIENTS WITH CANCER BY USING PATIENT-GENERATED SUBJECTIVE GLOBAL ASSESSMENT SHORT FORM (PG-SGA-SF)
}

\author{
Maha Almatary $^{1}$, Fatma Ghait ${ }^{2}$, Hajer Mohammed ${ }^{3}$, Ali Ateia Elmabsout ${ }^{4}$ \\ ${ }^{1,2,3,4}$ Department of Nutrition, Faculty of Public Health, University of Benghazi, Benghazi, Libya.
}

*Address for correspondence: Dr. Ali Ateia Elmabsout, Department of Nutrition, Faculty of Public Health, University of Benghazi, Benghazi, Libya.

Article DOI: https://doi.org/10.36713/epra8405

DOI No: 10.36713/epra8405

\begin{abstract}
Introduction: Cancer-related malnutrition has negative consequences are taken too lightly in most oncology wards. The objective of this study is to determine the malnutrition risk (MR)/malnutrition $(M N)$ in cancer patients using PG-SGA short form.

Methods: This cross sectional study was conducted with cancer patients in oncology unit at Benghazi medical center on 229 patients in which 107 male and 122 female. The data collected through PG-SGA short form and analyzed by either frequencies or by suing Chi-square for significant differences.

Results and discussion: The study enrolled 229 oncology patients. The mean age was $58.34 \pm 11.60$ years. One hundred and twenty tow (53.7.3\%) of the patients were female. The most common three tumor types were breast tumors (27.9\%) followed by colorectal cancer (14\%) whereas, almost similar report for lung, liver and upper GIT (10.9\%). (11.4\%) and $(11.8 \%)$ respectively. The mean BMI of the patients was $26.17 \pm 0.3 \mathrm{~kg} / \mathrm{m} 2$. According to PG-SGA short form of the patients

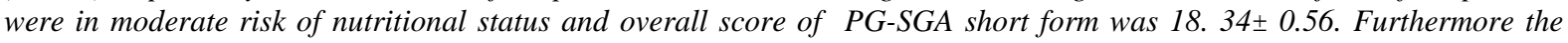
prevalence of cancer in this study was significant high in male $(P<0.05)$

Conclusion: In cancer patients, the risk of malnutrition is significantly high, and this may alter the patient's life quality and expectancy. Therefore, the nutritional status of the patient that is diagnosed with cancer should be assessed in early stages of the disease.
\end{abstract}

KEYWORDS: malnutrition, cancer, PG-SGA Nutrition Assessments

\section{INTRODUCTION}

Cancer-related malnutrition has negative impact and undertaking in most oncology wards [1]. There are many studies reported that malnutrition prevalence ranging from $25 \%$ to over $70 \%$ based on nutritional assessments. Certainly, people suffering from cancer are among the most malnourished of all patient groups [2-7]. Unfortunately, the health team particularly clinicians often miss malnutrition risk in cancer patients [8]. In addition, when malnutrition risk is recognized, it may not be adequately addressed. There is evidence from European hospitals showed that only one third of cancer patients at risk of malnutrition in fact received nutritional support [9-11]. The consequences of malnutrition will become serious if goes untreated, consequences can be serious [11].

Malnutrition led to increase the financial costs for managing cancer patients, which involvement the costs for longer hospital stays and higher rates of complications following cancer-related therapy [12]. Recent growing evidence shown that the most severe, patients who were malnourished had a 2- to 5-fold higher risk of dying compared to patients with little or no malnutrition [13]. Indeed, due to generally lack or low awareness of cancer-associated malnutrition, the strategies were overlooked by many oncologist for taking early actions to prevent and treat anorexia, cachexia, and sarcopenia [14]. Furthermore, malnutrition in patients with cancer are a result from insufficient nutritional intake that lead to a depletion of body stores of fat and lean mass, and 
eventually result in reduced physical function [15]. People with cancer may have appetite loss resulting from altered appetite signals [16].

With cancer progress, the loss of skeletal muscle is considered the potent negative prognostic factor for people of any body mass index (BMI) [17]. Furthermore, when skeletal muscle mass loss there will be higher risk of toxicity from chemotherapy, which result in reducing time to tumor progression, poor surgical outcome, physical disability, and increased mortality [18].

The Patient-Generated Subjective Global Assessment (PG-SGA) is well established in clinical setting as the reference method for assessing nutrition status in patients with cancer [19]. The modified version of the nutritional assessment instrument Subjective Global Assessment can be completed by the patients, and have been used as a method for screening of nutritional risk/ deficit and is referred to as PG-SGA Short Form [20]. In Libya the incidence of cancer is lower than other neighbored countries and according to previous work the top two frequently diagnosed malignancies in males were lung cancer (19\%) and colorectal cancer (10\%) and among females, include breast cancer (26\%), and colon and rectum cancer [21].Considerably, according to the literature, in Libya, cancer is second main cause of death (13\%) after cardiovascular disease (37\%) [22]. Therefore, the aim of the present study was to investigate malnutrition in patients with cancer by using PGSGA short form.

\section{MATERIAL AND METHODS Subjects and Methods}

Cross sectional study were conducted for all subjects (aged 18 y and over) from oncology unit at Benghazi medical center from beginning of January to end of March. Male and female included in the study were 107 and 122 respectively. Exclusion criteria were those younger than 18 years old and recently diagnosed cancer. Weight of the patients were measured at nearest $0.1 \mathrm{~kg}$ and height of the patients were also measured nearest $0.2 \mathrm{~cm}$ by weight balance SECA and Tape meter. BMI calculated as describe and categorized by WHO [23] through body weight in Kg divided height in meter Square while BMI categorized according to WHO [23] if < 18.5 underweight, 18.5-24.9 normal weight, 25-29.9 overweight and 30 and more is obese.

\section{Nutritional Assessment}

Nutritional status was assessed by PG-SGA Short Form. The English version of PG-SGA Short form was used in this work [24]. The PG-SGA Short form consisting of four text boxes include Box 1, patients report on current and former body weight; Box 2, changes in food intake and current type of food/nutritional intake; Box 3 nutritional impact symptoms and other factors influence food intake/absorption/utilization of nutrients; and lastly Box 4, for activities and function [24]. The numerical scoring was presented as range from 0 (no problems) to 36 (worst problem). For details Box 1 has a maximum score of 5, Box 2 has a maximum score of 4 , Box 3 has a maximum score of 24, and Box 4 has a maximum score of 3 .

According to PG-SGA Short form the risk of malnutrition was categorized as following : low (PG-SGA SF 0-3, SNAQ 0-1 points), medium (resp. 4-8 and 2 points), and high risk (resp. $\geq 9$ and $\geq 3$ points). In addition, malnutrition was defined as PG-SGA Stage B (moderate/suspected malnutrition) or Stage C (severely malnourished).

\section{Statistical analysis and ethics}

Statistical analyses were conducted using Statistical Package for Social Science 23.0 (SPSS) statistics program. Statistical significance was set at $\mathrm{p}<0.05$. The descriptive analyses of the normally distributed variables were presented as mean and standard deviation.

Categorical data was assessed using the Chi-square test or Fisher's exact test while quantitive data analyzed by $\mathrm{T}$ test.

The ethical approval was obtained from the local Ethical Commission of Benghazi medical center by formal consent.

\section{RESULTS}

Two hundred twenty nine patients gave their consent to participate in the study, resulting in a response rate of $99 \%$. Data for the 229 participants (aged 20-86 years old) with mean age was $58.34 \pm 11.60$ years; $46.7 \%$ male and 53.3\% were female included (Table 1). The age groups between 41-60 years old were predominant which represent $60.3 \%(\mathrm{p}<0.05)$ followed by age groups 61-86 years old and 24- 40 years old $28.4 \%$ and $10.5 \%$ respectively and being least were age group between $20-25$ years old $(0.9 \%)($ Table 2$)$.

Table 1: Gender distribution of the patients 


\begin{tabular}{|cl|c|c|}
\hline Gender & & $\mathbf{N}$ & $\mathbf{N} \%$ \\
\hline & Male & 107 & $46.7 \%$ \\
& female & 122 & $53.3 \%$ \\
& Total & 229 & $100.0 \%$ \\
\hline
\end{tabular}

Table 2: Age Distribution of the patients

\begin{tabular}{|r|c|c|c|}
\hline Ages (Year) & Count & Column N \% & P values \\
\hline $20-25$ & 2 & $0.9 \%$ & \\
$26-40$ & 24 & $10.5 \%$ & \\
$41-60$ & 138 & $60.3 \%$ & 0.000 \\
$61-86$ & 65 & $28.4 \%$ & \\
Total & 229 & $100.0 \%$ & \\
\hline
\end{tabular}

Chi-square test was performed and considered significant at $\alpha<0.5$

Types of cancer have been investigated among patients, by which more cancer reported is that breast $(27.9 \%)$ followed by colorectal cancer $14 \%$ whereas, almost similar report for lung, liver and upper GIT 10.9\%. 11.4\% and $11.8 \%$ respectively. Gynecology and bone were recorded by $5.7 \%$ and $5.2 \%$ respectively. Brain being lowest reported $(3.5 \%)$ table (3).

Table 3: Types of cancers among the participants

\begin{tabular}{|l|c|c|}
\hline \multicolumn{1}{|c|}{ Types of cancer } & N & N \% \\
\hline breast & 64 & $27.9 \%$ \\
Colorectal & 32 & $14.0 \%$ \\
lung & 25 & $10.9 \%$ \\
Liver and pancreas & 26 & $11.4 \%$ \\
Upper GIT & 27 & $11.8 \%$ \\
Prostate & 8 & $3.5 \%$ \\
Gynecology & 13 & $5.7 \%$ \\
brain & 8 & $3.5 \%$ \\
bone & 12 & $5.2 \%$ \\
Other (renal, skin, leukemia and & 14 & $6.1 \%$ \\
thyroid & 229 & $100.0 \%$ \\
Total & \\
\hline
\end{tabular}

In regarding Types of cancer among male and female as shown in table 9, breast and Gynecology cancers were confined to the female while prostate cancer confined to the male. The highest significant $(\mathrm{p}>0.05)$ of cancer in male were as following lung, liver, brain and bone, whereas non-significant increased upper GIT and other cancer have been reported. (Table 4). 
EPRA International Journal of Multidisciplinary Research (IJMR) - Peer Reviewed Journal

Volume: 7| Issue: 9| September 2021|| Journal D0I: 10.36713/epra2013 || SJIF Impact Factor 2021: 8.047 || ISI Value: 1.188

Table 4: Types of cancer among the participants:

\begin{tabular}{|l|c|c|c|c|c|c|c|}
\hline \multirow{2}{*}{ Types of cancer } & \multicolumn{9}{|c|}{ Gender } & \multicolumn{2}{c|}{ P values } \\
\cline { 2 - 9 } & \multicolumn{2}{|c|}{ Male } & \multicolumn{2}{|c|}{ Female } & \multicolumn{2}{c|}{ Total } & N \% \\
\cline { 2 - 9 } breast & $\mathbf{N}$ & $\mathbf{N} \%$ & $\mathbf{N}$ & $\mathbf{N} \%$ & $\mathbf{N}$ & $\mathbf{N}$ & \\
colorectal & 0 & $0.0 \%$ & 64 & $52.5 \%$ & 64 & $27.9 \%$ & \\
lung & 15 & $14.0 \%$ & 17 & $13.9 \%$ & 32 & $14.0 \%$ & 0.43 \\
Liver and pancreas & 22 & $20.6 \%$ & 3 & $2.5 \%$ & 25 & $10.9 \%$ & 0.000 \\
Upper GIT & 19 & $17.8 \%$ & 7 & $5.7 \%$ & 26 & $11.4 \%$ & 0.019 \\
Prostate & 17 & $15.9 \%$ & 10 & $8.2 \%$ & 27 & $11.8 \%$ & 0.17 \\
Gynecology & 8 & $7.5 \%$ & 0 & $0.0 \%$ & 8 & $3.5 \%$ & \\
Brain & 0 & $0.0 \%$ & 13 & $10.7 \%$ & 13 & $5.7 \%$ & \\
Bone & 7 & $6.5 \%$ & 1 & $0.8 \%$ & 8 & $3.5 \%$ & 0.034 \\
Others(renal, skin, leukemia, & 10 & $9.3 \%$ & 2 & $1.6 \%$ & 12 & $5.2 \%$ & 0.021 \\
thyroid) & 9 & $8.4 \%$ & 5 & $4.1 \%$ & 14 & $6.1 \%$ & 0.12 \\
\hline
\end{tabular}

Chi-square test was performed and considered significant at $\alpha<0.5$

In the table $5 \mathrm{~A}$, BMI for the participants shown that, normal body weight was dominant and presented by about $44 \%$ while overweight came in the second with $38.9 \%$, obese participants represent by $13.1 \%$, and underweights were being the least $4.4 \%$. The percentages of significant weight loss during the last month was reported approximately $4.34 \%$ by which patients have moderate malnutrition (Table 5B).

Table 5 A: BMI categories among participants:

\begin{tabular}{|c|c|}
\hline BMI categories & $\mathrm{N}(\mathrm{N} \%)$ \\
\hline Underweight & $10(4.4 \%)$ \\
Normal weight & $100(43.7 \%)$ \\
Overweight & $89(38.9)$ \\
Obese & $30(13.1 \%)$ \\
Total & $229(100 \%)$ \\
\hline
\end{tabular}

Table 5 B: Body mass index and percentages weight loss

\begin{tabular}{|l|c|}
\hline & Mean \pm SEM \\
\hline Current BMI & $26.17 \pm 0.38$ \\
Last month BMI & $27.19 \pm 0.42$ \\
Weight loss during & $4.34 \%$ \\
last month & \\
\hline
\end{tabular}

In the analyses of PG-SGA SF presented in Table 6 the first component Box 1 is regarding weight status and weight changes during the last was shown that $69.1 \%$ of the participants have significant weight reduction $(P<0.000)$ (Table 6).

Table 6:Components of PG-SGA Short Form weight changes (Box 1)

\begin{tabular}{|l|r|r|r|}
\hline $\begin{array}{l}\text { Weight of the patients } \\
\text { during last two weeks }\end{array}$ & $\mathrm{N}$ & $\mathrm{N} \%$ & P values \\
(Box 1) & 31 & $13.5 \%$ & \\
\hline Increase r & 160 & $69.0 \%$ & 0.000 \\
Decreased & 38 & $16.5 \%$ & \\
Unchanged & 229 & $100.0 \%$ & \\
& & Total &
\end{tabular}

Chi-square test was performed and considered significant at $\alpha<0.5$ 
Furthermore analysis of Box 2 in PG-SGA SF which presented the food intake of the participants in which, 73\% of participants reported that their intake last month is less than normal this means decreased food intake which presented in patients indicated that patients have moderate malnutrition (Table $7 \mathrm{~A}$ ).

Table 7 A: Components of PG-SGA Short Form food intakes (Box 2)

\begin{tabular}{|c|c|c|c|}
\hline $\begin{array}{l}\text { Food intake (rate my intake } \\
\text { during the past month (Box 2) }\end{array}$ & Count & Column N \% & $\mathrm{P}$ values \\
\hline $\begin{array}{l}\text { unchanged } \\
\text { less than normal } \\
\text { more than normal }\end{array}$ & $\begin{array}{r}57 \\
167 \\
5 \\
229\end{array}$ & $\begin{array}{r}24.9 \% \\
72.9 \% \\
2 . .2 \% \\
100.0 \%\end{array}$ & 0.000 \\
\hline
\end{tabular}

Chi-square test was performed and considered significant at $\alpha<0.5$

However further analysis of food intake of participant in Box 2 of PG-SGA Short Form found that current food intake, by which very little of anything reported the highest percentages among the participants (55\%) (Table 7 B).

Table 7 B: Components of PG-SGA Short Form food intakes (Box 2)

\begin{tabular}{|l|c|}
\hline Food intake (I am now taking) (Box 2) & $\mathrm{N}(\mathrm{N} \%)$ \\
\hline normal food but less than normal & $48 / 229(21 \%)$ \\
little solid food & $0 / 229(0 \%)$ \\
only liquid & $9 / 229(3.9 \%$ \\
only nutritional supplements & $26 / 229(13.4 \%)$ \\
very little of anything & $126 / 229(55 \%)$ \\
only tube feeding or only nutrition by vein & $8 / 229(3.5 \%)$ \\
& \\
\hline
\end{tabular}

In the PG-SGA Short Form, the third component of assessing nutritional status of the participants were that, symptoms (Box 3), most participants reported that $82.5 \%$ and $71.6 \%$ for nausea and no appetite respectively. In general the rest of the symptoms in the Box 3 of PG-SGA Short Form were found less than 50\% (Table 8 A).

Table 8 A: Components of PG-SGA Short Form symptoms (Box 3)

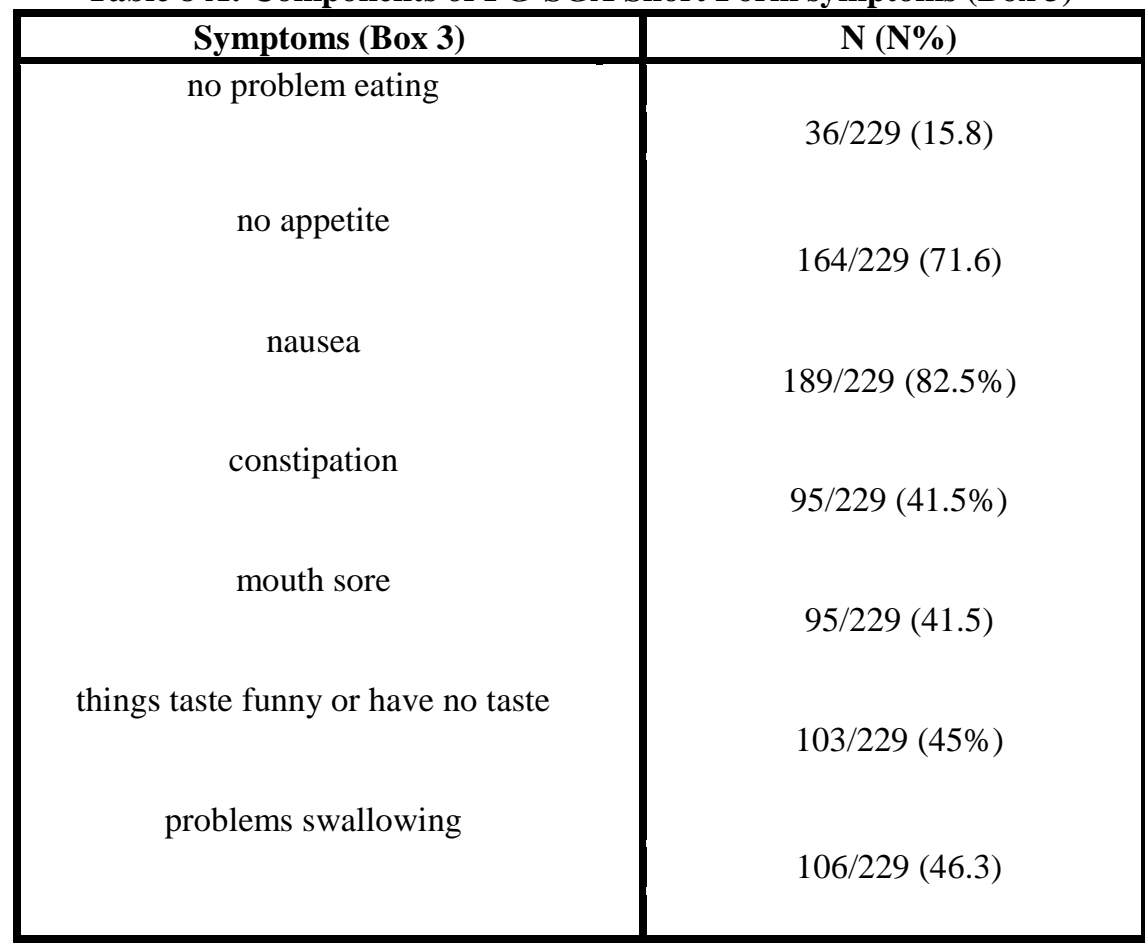


The analysis of PG-SGA Short Form in the Box 3 shown that, participants were highly reported the following symptoms: vomiting, diarrhea, dry mouth, smell bother me, fell full quickly, and fatigue as $51.3 \%, 51.3 \%$, $76.4 \%, 65.5 \%, 53.7 \%$ and $91.3 \%$ respectively (Table 8 B).

Table 8 B: Components of PG-SGA Short Form symptoms (Box 3)

\begin{tabular}{|c|c|c|}
\hline \multicolumn{2}{|c|}{ Symptoms (Box 3) } & $\mathrm{N}(\mathrm{N} \%)$ \\
\hline \multirow{8}{*}{ Pymptoms (1 } & No & $160(69.8)$ \\
\hline & abdominal & $6(2.6 \%)$ \\
\hline & Back/ Joint pain & $45(19.6)$ \\
\hline & chest & $3(1.3 \%)$ \\
\hline & general pain & $6(2.6 \%)$ \\
\hline & headache & $5(2.2 \%)$ \\
\hline & shoulder & $4(1.7 \%)$ \\
\hline & Total & $229(100 \%)$ \\
\hline \multicolumn{2}{|l|}{ vomiting } & $117 / 229(51.3 \%)$ \\
\hline \multicolumn{2}{|l|}{ diarrhea } & $117 / 229(51.3 \%)$ \\
\hline \multicolumn{2}{|l|}{ dry mouth } & $175 / 229(76.4 \%)$ \\
\hline \multicolumn{2}{|c|}{ smell bother me } & $150 / 229(65.5 \%)$ \\
\hline \multicolumn{2}{|c|}{ fell full quickly } & $123 / 229(53.7 \%)$ \\
\hline \multicolumn{2}{|l|}{ fatigue } & $209 / 229(91.3 \%)$ \\
\hline
\end{tabular}

In the last part of PG-SGA Short Form (Box 4) which represent the function and activities of patients. Approximately $39.3 \%$ of the participants reported that able to little activity spend most of the day in bed or chair while the remaining of the Box 4 components reported les that $28 \%$ (Table 9).

Table 9: Components of PG-SGA Short Form activities and functions (Box 4)

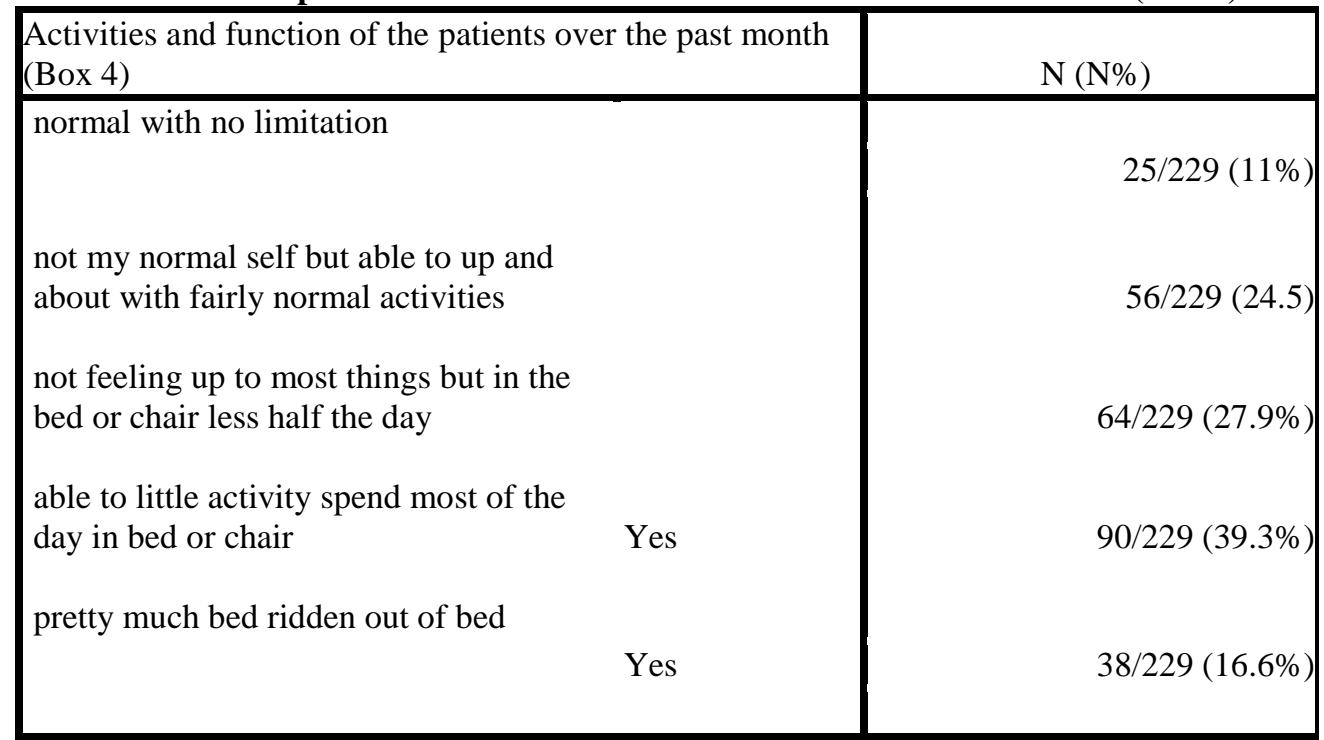


For the assessing of malnutrition for the participants by scoring or points each components of PG-SGA Short Form, the PG-SGA short form questionnaire categorized the total points as the following low risk malnutrition (0-3 points), medium risk malnutrition( $4-8$ points) high risk malnutrition ( $\geq 9$ points).

The result in table 10, found that total points were 18.34 which mean patients have or needs for improved symptoms managements and or nutrients intervention options according to PG-SGA Short Form listed (Table 10).

Table 10:Categories of PG-SGA SF components

\begin{tabular}{|l|c|}
\hline Categories of PG-SGA SF & Mean \pm SEM \\
\hline Weight changes (Box1) & $0.71 \pm 0.03$ \\
Food intake (Box 2) & $2.86 \pm 0.10$ \\
Symptoms (Box 3) & $12.28 \pm 0.41$ \\
Activities (Box 4) & $2.49 \pm 0.12$ \\
Total points (scores) & $18.34 \pm 0.56$ \\
\hline
\end{tabular}

Table 11 shown that all types of cancer reported total points $>9$, this indicated patient have high risk malnutrition which mean all participants need for improved symptoms managements and or nutrients intervention options (Table 11).

Table 11: Malnutrition Risk Among The Participants

\begin{tabular}{|l|c|c|c|c|c|}
\hline & $\begin{array}{c}\text { weight status } \\
\text { (Box 1) }\end{array}$ & $\begin{array}{c}\text { food intake } \\
\text { (Box 2) }\end{array}$ & $\begin{array}{c}\text { Symptoms } \\
\text { (Box 3) }\end{array}$ & $\begin{array}{c}\text { activities and } \\
\text { function } \\
\text { (Box 3) }\end{array}$ & Risk malnutrition \\
\cline { 2 - 6 } Types of cancer & Mean \pm SEM & Mean \pm SEM & Mean \pm SEM & Mean \pm SEM & Total Mean \pm SEM \\
\hline Breast & $.69 \pm 0.6$ & $2.64 \pm 0.19$ & $11.86 \pm 0.75$ & $2.50 \pm 0.26$ & $17.69 \pm 1.07$ (high) \\
Colorectal cancer & $.78 \pm 0.7$ & $2.69 \pm 0.20$ & $11.53 \pm 1$ & $2.44 \pm 0.29$ & $17.44 \pm 1.44(\mathrm{high})$ \\
lung & $.68 \pm 0.1$ & $2.96 \pm 0.24$ & $12.92 \pm 1.25$ & $2.08 \pm 0.24$ & $18.64 \pm 1.6(\mathrm{high})$ \\
Liver and pancreatic & $.62 \pm 0.1$ & $2.96 \pm 0.16$ & $12.23 \pm 2.1$ & $2.38 \pm 0.22$ & $18.19 \pm 1.7$ (high) \\
Upper GIT & $.70 \pm 0.19$ & $3.19 \pm 0.11$ & $12.26 \pm 2.1$ & $2.30 \pm 0.24$ & $18.44 \pm 1.8(\mathrm{high})$ \\
Prostate & $.75 \pm 0.16$ & $3.00 \pm 0.11$ & $12.00 \pm 2.5$ & $3.88 \pm 0.26$ & $19.63 \pm 3.4(\mathrm{high})$ \\
Gynecology & $.85 \pm 0.14$ & $3.00 \pm 0.9$ & $11.62 \pm 2.5$ & $1.85 \pm 0.21$ & $17.31 \pm 2.5$ (high) \\
Brain & $.75 \pm 0.11$ & $3.00 \pm 0.10$ & $14.25 \pm 2.6$ & $2.75 \pm 0.25$ & $20.75 \pm 3.1$ (high) \\
Bone & $.67 \pm 0.10$ & $3.17 \pm 0.11$ & $13.75 \pm 2.1$ & $2.58 \pm 0.28$ & $20.17 \pm 2.2(\mathrm{high})$ \\
Others (renal, skin, leukemia, & $.79 \pm 0.10$ & $2.79 \pm 0.12$ & $13.21 \pm 2.2$ & $3.50 \pm 0.25$ & $20.29 \pm 2.5$ (high) \\
thyroids) & $.71 \pm 0.11$ & $2.86 \pm 0.23$ & $12.28 \pm 2.4$ & $2.49 \pm 2.05$ & $18.34 \pm 2.7$ (high) \\
Total & &
\end{tabular}

In the next step, further investigation of malnutrition through percentages of weight loss. According to PG-SGA Short Form, moderate malnutrition if weight loss during one month is $\leq 5 \%$ and severe malnutrition if weight loss during last month is $>5 \%$. The result in the table 12 shown that all participants with types of cancers have moderate risk of malnutrition except those participants with brain cancer have sever risk of malnutrition. 
Table 12: Types of cancers, percentages of weight loss and risk of malnutrition:

\begin{tabular}{|l|c|c|}
\hline \multirow{2}{*}{ Types of cancer } & $\begin{array}{c}\text { Weight loss during } \\
\text { last month }\end{array}$ & Risk of malnutrition \\
\cline { 2 - 2 } Breast & Mean \pm SEM & Moderate \\
Colorectal & $4.46 \pm 1.03$ & Moderate \\
Lung & $3.67 \pm 2.03$ & moderate \\
Liver and pancreatic & $1.02 \pm 1$ & Moderate \\
Upper GIT & $4.01 \pm 2.23$ & Moderate \\
Prostate & $3.98 \pm 2.08$ & Moderate \\
Gynecology & $4.51 \pm 3$ & Moderate \\
Brain & $1.06 \pm 0.4$ & Severe \\
Bone & $7.45 \pm 3.2$ & Moderate \\
Other (renal, skin, leukemia, thyroid & $1.31 \pm 1$ & Moderate \\
\hline
\end{tabular}

\section{DISCUSSION}

In the oncology population where malnutrition is high, more descriptive screening tools is needed to give further information for assessing triaging and capture acute change. Among the effective screening tool is The Patient-Generated Subjective Global Assessment Short Form (PG-SGA SF) is a which used for descriptive nutrition screening [25].

The present study reveal that, the prevalent of cancer among male and female was shown by $46.7 \%$ and $53.3 \%$ respectively, because this study include the participant have different types of cancers. In regard the ages, All participants (aged $18 \mathrm{y}$ and over) commencing radiotherapy or chemotherapy. The most age groups affected by cancer those between $41-60$ years old $(\mathrm{p}<0.05)$ this find also confirmed in numbers of studies [26, 27]. However, some studies found that cancer mostly confined to age groups over 60 years old [28-31].

Regarding types of cancers our study shown that breast cancer reported the highest number $(27.9 \%)$ followed by colorectal cancer $14 \%$ whereas, almost similar report for lung, liver and upper GIT 10.9\%. $11.4 \%$ and $11.8 \%$ respectively. Gynecology and bone were recorded by $5.7 \%$ and $5.2 \%$ respectively. Brain being lowest reported (3.5\%). This figures were first highlighted in the present works. These trends were also in consistent with previous work by Davies by which the most prevalent tumors corresponded to breast, lung and colorectal cancer [32]. On the other hands, some researchers reported that the most prevalent cancer is colorectal, other GIT and breast cancer respectively [9,11]. Furthermore, that data collected from department of oncology in Benghazi medical center revealed that significant increased lung, liver and pancreas, bone and as well as brain cancer in male $(\mathrm{P}<0.05)$.In compare to male, breast, colorectal and gynecological cancer increased in female. These data were also established somewhere else [33, 34]. On the other hands, in the previous works colorectal cancers were more predominant in male and this result was not consistent with the present work [35].

In regarding BMI, the overall BMI of patients were overweight, by analyzed and categorized BMI revealed that approximately $45 \%$ of patients have normal body weight whereas more than $50 \%$ have been found overweight and obesity. Such works have been proved by Elena and et al [36], Unsal and et al [37] and Broeke and etal [38].

In the PG-SGA Short form (consisting of four text boxes), patients report on current and former body weight (Box 1); changes in food intake and current type of food/nutritional intake (Box 2); nutritional impact symptoms and other factors that negatively influence food intake/absorption/utilization of nutrients (Box 3); and activities and (Box 4). Further analysis of patients response to the questions in Box 1 (weight changes) were found significantly decreased $(\mathrm{p}<0.05)$ body weight during the last weeks $(69 \%)$. This could be contribute to overall $4.3 \%$ weight changes for all patients during the last month. However, about $39 \%$ and $13 \%$ of the patients have had either overweight or obesity respectively. The net weight loss reported for all BMI categories and weight changes by $4.3 \%$ this is the fact that indicated by significant decreased boy weight reported by patients in Box 1 question of PG-SGA Short form. Furthermore, based on PG-SGA Short form classification of weight loss $\leq 5 \%$ during the last 2 weeks indicated that patients have moderate malnutrition. The moderate malnutrition found in this study was not similar to that reported by Unsal and et al [37] by which high percentages of patients were low malnutrition. Although, Elen and et al [36] found that moderate malnutrition presented as much as $76 \%$. Further interpretation for moderate malnutrition just due to changes in food intake and current type of food/nutritional intake (Box 2 ) of PG-SGA Short which shown that about $73 \%$ of patients suffering 
from less food intake than normal $(\mathrm{p}<0.05)$ or very little intake of anything $(54 \%)$. In addition, the PG-SGA Short Form, in the third component of assessing nutritional status of the participants were that, symptoms (Box 3), most participants reported that $82.5 \%$ and $71.6 \%$ for nausea and no appetite respectively. These factors could contribute to malnutrition among the patients. Moreover, analysis of PG-SGA Short Form in the Box 3 shown that, participants were highly reported vomiting, diarrhea, dry mouth, smell bother me, fell full quickly, and fatigue as $51.3 \%, 51.3 \%, 76.4 \%, 65.5 \%, 53.7 \%$ and $91.3 \%$ respectively and those symptoms further implicated in loss of appetites and weight loss.

Further analysis of weight loss for each cancer shown that, all types of cancer with except of brain have moderate risk of malnutrition risk and for brain severe malnutrition risk. The result obtained from the present study considered highlighted finding because neither studies were consistent with the present finding. In the studies conducted by $[39,40]$ in patients with different types of cancers which were not similar to the our patients, the risk of malnutrition was moderately as overall risks by using Nutriscore.

While those studies used PG-SGA as a tool for assessing malnutrition pointed out the overall malnutrition as percentages [41, 42] Only very few studies were figure out malnutrition as moderately after used PG-SGA total score [24, 25].

The total scores or points obtained in this study from PG-SGA were 18which considered as high as than those previously described [43] and those patients need for improved symptoms managements and or nutrients intervention options. These result could be probably what were reported individually in PG-SGA components.

In sum, the present work highlighted some points by which all types of cancer have high risk of malnutrition which could be prone to protein energy malnutrition or cachexia. Furthermore all patients in studied samples need for improved symptoms managements and or nutrients intervention options. The prevalence of cancer was high in man. This study need to validity in large samples. Its highly recommended that nutrition screening and assessment strongly advocated in order to minimized protein energy malnutrition and/ or sarcopinia.

\section{CONCLUSION}

The present work reveal that, cancer prevalent was more predominate in female, and the most age affected by cancer those age groups between 41-60 years old, some types of cancer significant increase in male include lung, liver, bone and brain. On the words female patients have found increased breast, colorectal and gynecological cancer. Overall mean BMI of patients were overweight. Body mass indices reveal that approximately $45 \%$ of patients eutrophic weight and more than $50 \%$ were overweight and obese. Overall significant weight loss during the last months were $4.34 \%$ and this indicated that patients suffering from moderate malnutrition. About $73 \%$ of patients suffering from less intake of foods. Furthermore, the overall mean of PG-SGA SF score was 18 which mean patients have high risk for malnutrition and need for improved symptoms managements and or nutrients intervention options.

\section{Conflict of Interest}

No conflict of interest.

\section{Acknowledgments}

The acknowledgement for this work forwarded to all subjects involved in the study.

Sayeed MA, Hussain MZ, Rumi MAK, Khan AK. Prevalence of diabetes in a suburban population of Bangladesh. Diab Res Clin Pract. 1997; 34(1): 149-155.

\section{REFERENCES}

1. Nitenberg G, Raynard B. Nutritional support of the cancer patient: issues and dilemmas. Crit Rev Oncol Hematol. 2000;34:137-168.

2. Maasberg S, Knappe-Drzikova B, Vonderbeck D, Jann H, Weylandt KH, Grieser C, Pascher A, Schefold JC, Pavel $M$, Wiedenmann B, Sturm A, Pape UF. Malnutrition predicts clinical outcome in patients with neuroendocrine neoplasias. Neuroendocrinology. 2014; 104 :11-25.

3. Attar A, Malka D, Sabate JM, Bonnetain F, Lecomte T, Aparicio T, Locher C, Laharie D, Ezenfis J, Taieb J. Malnutrition is high and underestimated during chemotherapy in gastrointestinal cancer: an AGEO prospective cross-sectional multicenter study. Nutr Cancer. 2012;64:535-542.

4. Hebuterne X, Lemarie E, Michallet M, de Montreuil CB, Schneider SM, Goldwasser F. Prevalence of malnutrition and current use of nutrition support in patients with cancer. JPEN J Parenter Enteral Nutr. 2014;38:196-204.

5. Pressoir M, Desne S, Berchery D, Rossignol G, Poiree B, Meslier M, Traversier S, Vittot M, Simon M, Gekiere JP, Meuric J, Serot F, Falewee MN, et al. Prevalence, risk factors and clinical implications of malnutrition in French Comprehensive Cancer Centres. Br J Cancer. 2012;102:966-971. 
6. Planas M, Alvarez-Hernandez J, Leon-Sanz M, Celaya-Perez S, Araujo K, Garcia de Lorenzo A; PREDyCES® researchers. Prevalence of hospital malnutrition in cancer patients: a sub-analysis of the PREDyCES® study. Support Care Cancer. 2016;14:429-435.

7. Silva FR, de Oliveira MG, Souza AS, Figueroa JN, Santos CS. Factors associated with malnutrition in hospitalized cancer patients: a cross-sectional study. Nutr J. 2015;14:123.

8. Ryan AM, Power DG, Daly L, Cushen SJ, Ni Bhuachalla E, Prado CM. Cancer-associated malnutrition, cachexia and sarcopenia: the skeleton in the hospital closet 40 years later. Proc Nutr Soc.2016;75:1-13.

9. Gyan E, Raynard B, Durand JP, Lacau Saint Guily J, Gouy S, Movschin ML, Khemissa F, Flori N, Oziel-Taieb S, Bannier Braticevic C, Zeanandin G, Hebert C, Savinelli F, et al; NutriCancer 2012 Investigator Group. Malnutrition in patients with cancer. JPEN J Parenter Enteral Nutr. 2017;5:123-135.

10. Aaldriks AA, van der Geest LG, Giltay EJ, le Cessie S, Portielje JE, Tanis BC, Nortier JW, Maartense E. Frailty and malnutrition predictive of mortality risk in older patients with advanced colorectal cancer receiving chemotherapy. J Geriatr Oncol. 2013;4: 218-226.

11. Planas M, Alvarez-Hernandez J, Leon-Sanz M, Celaya-Perez S, Araujo K, Garciade Lorenzo A, et al. Prevalence of hospital malnutrition in cancer patients: a subanalysis of the PREDyCES study. Support Care Cancer. 2016;24: 429-35.

12. Orrevall Y, Tishelman C, Permert J, Cederholm T. Nutritional support and risk status among cancer patients in palliative home care services. Support Care Cancer2019;17:153-61.

13. Segura A, Pardo J, Jara C, Zugazabeitia L, et al. An epidemiological evaluation of the prevalence of malnutrition in Spanish patients with locally advanced or metastatic cancer. Clin Nutr. 2005;24: 801-14.

14. Arribas L, Hurtós L, Sendrós MJ, Peiró I, Salleras N, Fort E, Sanchez-Migallon JM. Nutriscore: A new nutritional screening tool for oncological outpatients. Nutrition.2017;33:297-303.

15. Fearon K, Strasser F, Anker SD, Bosaeus I, Bruera E, Fainsinger RL, Jatoi A, Loprinzi C et al. Definition and classification of cancer cachexia: an international consensus. Lancet Oncol. 2011;12:489-95.

16. Pastore CA, Orlandi SP, Gonzalez MC. The Inflammatory-Nutritional Index;assessing nutritional status and prognosis in gastrointestinal and lung cancer patients. Nutr Hosp. 2014;29:629-34.

17. Read JA, Crockett N, Volker DH, MacLennan P, Choy ST, Beale P, et al. Nutritional assessment in cancer: comparing the Mini-Nutritional Assessment (MNA) with the scored Patient-Generated Subjective Global Assessment (PGSGA). Nutr Cancer. Nutr Cancer.2005; 53: 51-56.

18. Gheorghe C, Pascu O, Iacob R, Vadan R, Iacob S, Goldis A, et al. Nutritional riskscreening and prevalence of malnutrition on admission to gastroenterology departments: a multicentric study. Chirurgia (Bucur). 2013;108:535-541

19. Arribas L, Hurtós L, Sendrós MJ, Peiró I, Salleras N, Fort E, Sanchez-Migallon JM.

20. Nutriscore: A new nutritional screening tool for oncological outpatients. Nutrition. 2017;33: 297-303.

21. Harri"et Jager-Wittenaar, Hester F. de Bats, Bertine J. Welink-Lamberts, and et al. Self-Completion of the Patient-Generated Subjective Global Assessment Short Form Is Feasible and Is Associated With Increased Awareness on Malnutrition Risk in Patients Within Head and Neck Cancer Nutrition in Clinical Practice. 2020;35: 353-362.

22. Trude $R$ Balstad, Asta Bye, Cathrine RS Jenssen, Tora S Solheim, Lene Thoresen, Kari Sand. Patient interpretation of the Patient-Generated Subjective Global Assessment (PG-SGA) Short Form. Patient Preference and Adherence. 2019;13:1391-1400

23. 22. Gellrich NC, Handschel J, Holtmann H, Kruskemper G. Oral cancer malnutrition impacts weight and quality of life. Nutrients. 2015;7:2145-2160.

24. Bouchard, D.R.; Ross, R.; Janssen, I. Coffee, tea and their additives: Association with BMI and waist circumference. Obes. Facts. 2010;3:345-352.

25. Jessica Abbott, L. Teleni, D. McKavanagh, and J. Watson. Patient-Generated Subjective Global Assessment Short Form (PG-SGA SF) is a valid screening tool in chemotherapy outpatients. Supportive Care in Cancer. 2016;24:3883-3887

26. Kim YJ, Hui D, Zhang Y, Park JC, Chisholm G, Williams J, et al. Differences in performance status assessment among palliative care specialists, nurses, and medical oncologists. J Pain Symptom Manage. 2015;49:1050-1058.

27. Wie GA, Cho YA, Kim SY, Kim SM, Bae JM, Joung H, et al. Prevalence and risk factors of malnutrition among cancer patients according to tumor location and stage in the National Cancer Center in Korea. Nutr. 2015;26:263-268.

28. Marian AE. Nutritional support strategies for malnourished cancer patients. Eur J Oncol Nurs. 2005;9: 74-83.

29. Korfali G, Gündoğdu H, Aydintuğ S, Bahar M, Besler T, Moral AR, et al. Nutritional risk of hospitalized patients in Turkey. Clin Nutr.2009;28:533-53

30. Hebuterne X, Lemarie E, Michallet M, de Montreuil CB, Schneider SM, Goldwasser F. Prevalence of malnutrition and current use of nutrition support in patients with cancer. J Parenter Enteral Nutr. 2014;38: 196e204.

31. Melchior JC, Preaud E, Carles J, Brami M, Duru G, Fontaine E, Hebuterne X, Lukacs B, Zazzo JF, Panis Y, Nitenberg G. Clinical and economic impact of malnutrition per se on the postoperative course of colorectal cancer patients. Clin Nutr. 2012;31:896-902.

32. Blauwhoff-Buskermolen S, Ruijgrok C, Ostelo RW, de Vet HC, Verheul HM, de van der Schueren MA, Langius JA. The assessment of anorexia in patients with cancer: cut-off values for the FAACT-A/CS and the VAS for appetite. Support Care Cancer. 2016;24: 661-666. 
33. Davies M. Nutritional screening and assessment in cancer-associated malnutrition. Eur J Oncol Nurs. 2005;9:Suppl 2:S64-73

34. Farhangfar A, Makarewicz M, Ghosh S, Jha N, Scrimger R, Gramlich L, Baracos V. Nutrition impact symptoms in a population cohort of head and neck cancer patients: multivariate regression analysis of symptoms on oral intake, weight loss and survival. Oral Oncol. 2014;50:877-883.

35. Dev R, Hui D, Chisholm G, Delgado-Guay M, Dalal S, Del Fabbro E, Bruera E. Hypermetabolism and symptom burden in advanced cancer patients evaluated in a cachexia clinic. J Cachexia Sarcopenia Muscle. 2015;6: 95-98.

36. McMillan DC. The systemic inflammation-based Glasgow Prognostic Score: a decade of experience in patients with cancer. Cancer Treat Rev. 2013;39:534-40.

37. Elena A lvaro Sanz, Marga Garrido Siles, Laura Rey Fern«andez, Rosa Villatoro Rold, Antonio Rueda Dom«õnguez), Jimena Abil « es. Nutritional risk and malnutrition rates at diagnosis of cancer in patients treated in outpatient settings. Early intervention protocol. The End-to-end Journal. 2018;5:21-30.

38. Unsal D, Bulent Mentes, , Muge Akmansu, , Aytug Uner, Mehmet Oguz, and Yucel Pak, MD. Evaluation of Nutritional Status in Cancer Patients Receiving Radiotherapy. A Prospective Study. Am J Clin Oncol. 2006;29:183-188.

39. Fruchtenicht AVG, Poziomyck AK, Kabke GB, Loss SH, Antoniazzi JL, Steemburgo T, et al. Nutritional risk assessment in critically ill cancer patients: systematic review. Rev Bras Ter Intensiva. 2015;27:274-283.

40. Lee JLC, Leong LP, Lim SL. Nutrition intervention approaches to reduce malnutrition in oncology patients: a systematic review. Support Care Cancer. 2016;24:469-80.

41. Sarikaya D, Halil M, Kuyumcu ME, Kilic MK, Yesil Y, Kara O, et al. Mini nutritional assessment test long and short form are valid screening tools in Turkish older adults. Arch Gerontol Geriatr. 2015;61:56-60.

42. Marín Caro MM, Laviano A, Pichard C. Nutritional intervention and quality of life in adult oncology patients. Clin Nutr. 2007;26:289-301.

43. Santarpia L, Contaldo F, Pasanisi F. Nutritional screening and early treatment of malnutrition in cancer patients. J Cachexia Sarcopenia Muscle. 2011;2: 27-35.

44. Leuenberger M, Kurmann S, Stanga Z. Nutritional screening tools in daily clinical practice: the focus on cancer. Support Care Cancer. 2010;18:S17-27. 